\title{
Comparison of the effects of superior colliculus and pulvinar lesions on visual search and tachistoscopic pattern discrimination in monkeys
}

\author{
D. B. Bender and C.M. Butter \\ Department of Physiology, University at Buffalo, State University of New York, Medical School, 4234 Ridge Lea Rd., \\ Buffalo, NY 14226, USA \\ and Neuroscience Laboratory and Psychology Department, The University of Michigan, Ann Arbor, MI 48109, USA
}

\begin{abstract}
Summary. In order to investigate whether pulvinar lesions produce behavioral impairments similar to those that follow superior colliculus lesions, monkeys were tested on a visual search task before and after receiving radiofrequency lesions of either the superior colliculus or pulvinar. The animals searched for a small target pattern within an array of varying numbers of irrelevant patterns. After receiving colliculus lesions, the animals showed marked postoperative increases in either search time, percent errors, or both. By contrast, pulvinar lesions had little or no effect on visual search performance. Similarly, in learning to search for a target they had not previously seen, animals with colliculus lesions were impaired relative to unoperated controls, whereas pulvinar-lesioned animals did not differ from controls. In an attempt to confirm the finding that pulvinar lesions impair tachistoscopic pattern discrimination, we determined exposure-duration thresholds of pulvinar- and colliculus-lesioned monkeys for performance of a pattern discrimination. The thresholds of the colliculus-lesioned monkeys were elevated 20 -fold relative to controls. By contrast, thresholds of the pulvinar-lesioned monkeys were normal. We conclude that the pulvinar is not critical for the attentional processes in which the superior colliculus participates.
\end{abstract}

Key words: Pulvinar - Superior colliculus - Visual search - Monkey - Tachistoscopic discrimination

\section{Introduction}

Extensive evidence from both electrophysiological (Bender 1981, 1982, 1983; Petersen et al. 1985) and

Offprint requests to: D. B. Bender, Department of Physiology, Buffalo (address see above) anatomical investigations (Benevento and Davis 1977; Benevento and Fallon 1975; Benevento and Rezak 1976; Campos-Ortega and Hayhow 1972; Chow 1950; Harting et al. 1980; Ogren and Hendrickson 1976; Partlow et al. 1977; Whitlock and Nauta 1956) indicates that the primate pulvinar participates in visual functions. Yet, most attempts to demonstrate behavioral deficits in monkeys following pulvinar lesions have yielded negative results (Chow 1954; Mishkin 1972; Ungerleider et al. 1977; Ungerleider and Pribram 1977), even though performance in the same tasks is impaired by lesions of visual cortex (Gross 1973; Keating 1975; Mishkin 1972).

In an effort to resolve this discrepancy, we suggested (Leiby et al. 1982) that the pulvinar may participate in some of the visual functions of the superior colliculus, a structure from which it receives topographically organized projections (Benevento and Fallon 1975; Partlow et al. 1977; Harting et al. 1980). On this view, one should expect that performance of visual tasks sensitive to lesions of the superior colliculus would also be impaired by lesions of the tecto-recipient portions of the pulvinar. The present study is the third in a series of experiments undertaken to evaluate this hypothesis. In the two previous experiments, the tasks involved localization and detection of brief light flashes in the periphery of the visual field (Leiby et al. 1982) and color discrimination in which the visual cues were spatially separated from the response sites (Nagel-Leiby et al. 1984). Whereas lesions of the colliculus severely impaired performance on these tasks (Butter et al. 1978; Butter 1974), both studies suggested that loss of pulvinar neurons does not impair performance.

In the present study, we compared the performance in a visual search task of animals with colliculus lesions and animals with pulvinar lesions. The task involved searching for a single, small target pattern in an array of small, irrelevant patterns. An observing 
response was used so that the monkey's gaze was directed toward the center of the stimulus array at the start of each trial. Azzato and Butter (1984) found that the search times of intact monkeys in this task increased linearly with the number of irrelevant patterns and with eccentricity of the target, suggesting that the monkeys shifted their gaze and attention serially through the display. We chose this particular task in the present study for several reasons. First, its performance requires the spatial shifts of attention that accompany eye movements, and the superior colliculus has been implicated in shifting attention on the basis of both electrophysiological (Goldberg and Wurtz 1972; Wurtz and Mohler 1976) and behavioral findings (Butter 1979; Kurtz et al. 1982). Furthermore, visual search performance is sensitive to superior colliculus lesions (Latto 1978). Finally, the pulvinar itself has been implicated in the control of attention by studies using electrophysiological recording (Gould et al. 1974), ablation (Chalupa et al. 1976), and injection of GABA-related drugs (Petersen et al. 1984).

Another goal of the present study was to further evaluate the possibility that damage to the corticotectal tract, which passes through the pulvinar, impairs performance in visual tasks sensitive to superior colliculus lesions. Radiofrequency (RF) lesions of the pulvinar, which can severely damage the corticotectal tract (Bender and Baizer 1984), impaired performance of a color discrimination task in which the cues were separated from the response sites. In contrast, kainic acid lesions, which spare fibers of passage, did not impair performance in that task (Nagel-Leiby et al. 1984). Similarly, RF lesions of the pulvinar produce abnormal scanning of a complex visual scene (Ungerleider and Christensen 1979), whereas kainic acid lesions of the pulvinar do not (Bender and Baizer 1986). Furthermore, in the study of Leiby et al. (1982), only those pulvinar lesions that extensively damaged the corticotectal fibers impaired localization and detection of light flashes. In the present experiment, we therefore initially used RF lesions, appropriately placed to destroy both the pulvinar and corticotectal tract. We had intended to then make kainic acid lesions of the pulvinar proper, had deficits resulted from the RF lesions.

In the present study, we found, as expected, that superior colliculus lesions profoundly impair performance in the visual search task described above. Somewhat surprisingly, however, pulvinar lesions did not affect search performance. This finding raised the possibility that the pulvinar might conceivably play a critical role in visual search, but only during its initial stage, that is, when the animal is learning the relevant cues which distinguish the target from the distracting stimuli. This possibility was also suggested by the report that monkeys with pulvinar lesions are impaired in the postoperative learning of a difficult visual discrimination task, but are not impaired in retention of the task having learned it before surgery (Chalupa et al. 1976). Thus, we subsequently tested the animals with colliculus and pulvinar lesions, together with unoperated controls, in a task in which they were required to search for a target they had not previously seen. Once again, however, we found that colliculus lesions impaired learning of this task whereas pulvinar lesions did not.

Since we found no impairment following pulvinar lesions in tasks requiring attention, even in the presence of many distracting stimuli, it seemed appropriate to try to confirm the findings reported by Chalupa et al. (1976). They had found that lesions of the inferior pulvinar impair the acquisition of a pattern discrimination task in which the patterns are exposed very briefly on each trial, and had interpreted this finding as evidence that the pulvinar is involved in the control of attention, particularly in tasks that include distracting stimuli. However, the tachistoscopic pattern discrimination used by Chalupa et al., which was extremely difficult for the rhesus monkeys in that study to learn, proved too difficult for the cynomolgus monkeys in the present study, a result not surprising since cynomolgus monkeys are slower learners of visual discriminations than rhesus monkeys (Leiby et al. 1978). Thus, we used a modified method of limits to determine the threshold exposure duration required to perform the same pattern discrimination that Chalupa et al. had used.

Some of these findings have been reported previously (Azzato et al. 1981).

\section{Methods}

\section{Subjects}

The subjects were nine cynomolgus monkeys (Macaca fascicularis), eight males and one female, weighing $2.9-5.3 \mathrm{~kg}$ at the beginning of the experiment. They were fed Purina monkey chow daily and received isoniazid ( $25 \mathrm{mg} /$ day) as prophylactic treatment against tuberculosis. During training and testing, their daily water intake was reduced to $100-120 \mathrm{cc}$.

The animals were divided into 3 groups of 3 animals each. Groups SC and PUL were trained preoperatively on visual search, given superior colliculus and pulvinar lesions, respectively, and then retested on visual search. They were subsequently tested in visual search for a new target and, finally, in the tachistoscopic discrimination task. Group UC served as an unoperated control group for the last two behavioral tests. It received the same training in visual search that was given preoperatively to groups SC and PUL. 


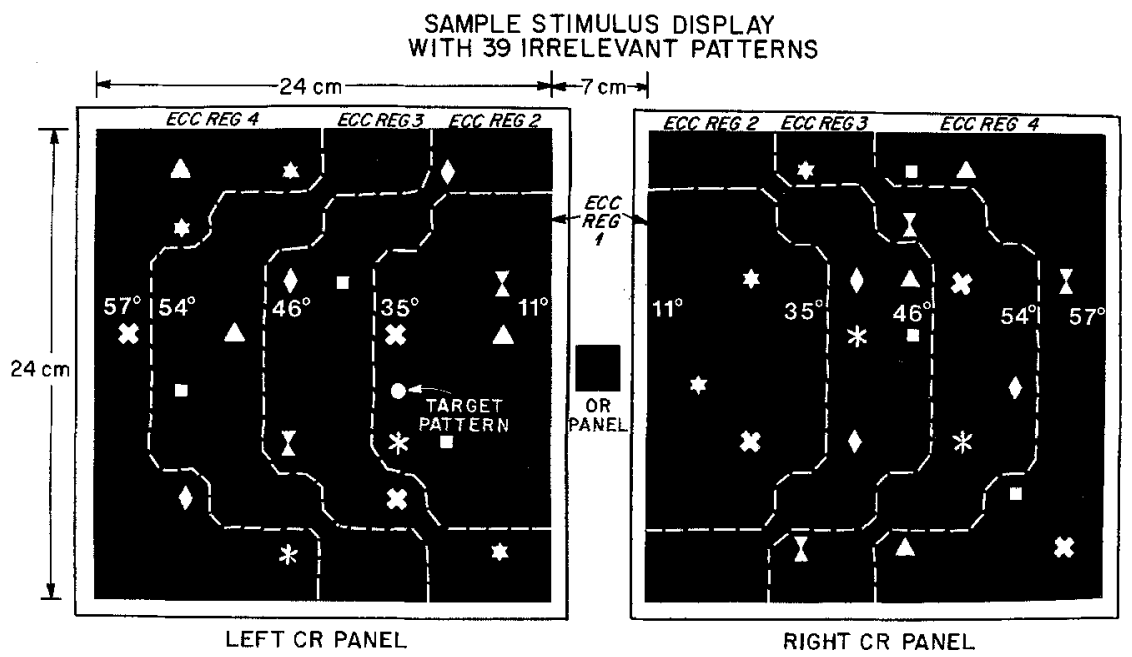

Fig. 1. Schematic representation of the display panels used in the visual search task, drawn to scale, showing 39 irrelevant patterns; left CR panel has target pattern and 19 irrelevant patterns, right panel has 20 irrelevant patterns. Four eccentricity regions (ECC REG) of approximately equal area are indicated by dashed lines (not displayed to subjects); the lines were defined by dividing each panel into an $8 \times 8$ matrix. (Reproduced by permission, from Azzato and Butter 1984)

\section{Behavioral procedures}

Visual search. Training and testing was carried out in a soundshielded, darkened chamber. The monkeys were restrained in a primate chair and faced two large choice-response (CR) panels on which patterns were rear-projected (see Fig. 1). At the viewing distance of approximately $18 \mathrm{~cm}$, each panel subtended $53^{\circ}$; the patterns were $2^{\circ}-4^{\circ}$ in size. A small central panel was located straight ahead, between the two CR panels (see Azzato and Butter 1984, for a complete description of the apparatus and procedures of training and testing). The animals first learned to press the $C R$ panel only when it was diffusely illuminated to obtain a water reward. Next, the monkeys were trained to press the central panel within $3 \mathrm{~s}$ after a small light spot appeared on it in order to illuminate the $\mathrm{CR}$ panel. They were required to perform this observing response in all subsequent sessions in order to initiate each trial.

The monkeys were next trained to press the CR panel on which the target pattern, a small disk, was projected while a varying number $(0,1,3,5,7$ or 9) of irrelevant patterns (distractors) of different shapes was also presented. The stimuli remained on the panels until the animal pressed one of the panels. The animals required 37-59 sessions of this visual search training in order to achieve $90 \%$ correct responses in each of three consecutive sessions with each of the numbers of distractors. Subsequently, four consecutive series of visual search tests, in each of which the monkeys were required to perform at $90 \%$ correct, were administered. In the first series, the target pattern, along with 0-9 irrelevant patterns, was presented at high contrast (13.1 $\mathrm{cd} / \mathrm{m}^{2}$; background luminance of the CR panels $\left.=1.27 \mathrm{~cd} / \mathrm{m}^{2}\right)$ in eight sessions. In the second test series, the target pattern was presented along with 39 irrelevant patterns, all at high contrast, in four sessions. The third and fourth test series were presented in the same manner as the first two, except that all the patterns were presented at low contrast $\left(1.31 \mathrm{~cd} / \mathrm{m}^{2}\right)$. Methods of testing were otherwise the same as those employed in visual search training. One monkey (SC-2) was not tested with 39 irrelevant patterns in the low contrast condition. At the completion of preoperative training, three of the animals (Group SC) received superior colliculus lesions and three (Group PUL) received pulvinar lesions (see below). Three to four weeks following surgery, the monkeys were retrained in the visual search task, first with 1 and then with 3 and 5 irrelevant patterns. They were then retested in the same manner that they had been before surgery. Two of the monkeys (SC-1 and PUL-2) received control operations followed by search tests before they received lesions and further search testing.
Visual search for a new target. At the completion of testing on the visual search task, the monkeys were trained to search for a new target which they had not seen previously (the letter $L$ ), with the same linear dimensions as the disk that was the target used in the first visual search task. The target was presented along with the same nine irrelevant patterns used in the first search task, all at high contrast $\left(13.1 \mathrm{~cd} / \mathrm{m}^{2}\right)$. Each daily training session had 220 trials. Except for the change in the target pattern and a constant number of irrelevant patterns in each training session, the procedures were the same as those employed in the previous visual search testing. Training continued until the monkeys performed at least $90 \%$ correct responses in two consecutive sessions or until they completed 50 training sessions without meeting the criterion, whichever came first.

Tachistoscopic pattern discrimination. In all training and testing sessions, a trial was initiated only when the monkey first pressed the central panel when a spot appeared on it, as in the visual search tasks. In the first stage of training, pressing the central panel when the spot appeared on it resulted in a light appearing on one of the CR panels $\left(3.18 \mathrm{~cd} / \mathrm{m}^{2}\right.$; background luminance $\left.1.27 \mathrm{~cd} / \mathrm{m}^{2}\right)$; the panel on which the light appeared varied according to a pseudorandom series. The $\mathrm{CR}$ panel remained illuminated until the monkey pressed one of the CR panels or $5 \mathrm{~s}$ elapsed with no response, whichever came first. Depression of the illuminated panel was followed by a water reward; depression of the unilluminated panel resulted in an $8 \mathrm{~s}$ time-out period being added on to the variable $(3-8 \mathrm{~s})$ intertrial interval. Each training session consisted of 210 trials. Training in this stage was terminated when the monkeys performed at least $90 \%$ correct responses in a single session. In the second stage of training, the monkeys learned a light-flash detection task. The duration of the CR panel illumination was set at $2 \mathrm{~s}$ and then gradually reduced in steps to $10 \mathrm{~ms}$. At each exposure duration, $90 \%$ correct performance was required before reducing the duration further. Training terminated when the monkeys responded correctly to $10 \mathrm{~ms}$ flashes on at least $90 \%$ of the trials in each of two consecutive sessions.

The monkeys were next trained in a discrimination task in which a pair of patterns, one on each CR panel, was exposed for $10 \mathrm{~ms}$. The patterns were the same as those employed by Chalupa et al. (1976): an illuminated letter "N" (the positive stimulus) and the same pattern rotated $90^{\circ}$ (negative stimulus). At the viewing distance employed, the patterns were approximately $20^{\circ}$ in height and width; the thickness of the bars was approximately $5^{\circ}$. The center of the pattern was located approximately $20^{\circ}$ from the center of the fixation panel. The luminance of the pattern was the 
same as that of the light flash presented in the previous stage of training. After extensive training, several of the monkeys (UC-2, UC-3, SC-2, PUL-1 and PUL-2) adopted position habits (consistently pressing one of the panels) that could not be broken by a rerun correction procedure or by presenting the positive pattern only on the unpreferred panel. Therefore, the procedure was altered. The monkeys were first trained to discriminate between the two patterns which were presented until the animal made its choice response; next, the exposure duration of the patterns was reduced to threshold, using a titration procedure.

During the pattern-discrimination learning phase, each trial was initiated by a response on the central panel. The patterns were then exposed until the monkeys made their choice response or $5 \mathrm{~s}$ elapsed with no response, whichever came first. In all other respects, the procedures were the same as those used in the previous stage of training. The monkeys were trained to a criterion of $90 \%$ correct responses in a single session.

The titration procedure began immediately after patterndiscrimination learning. The exposure duration of the patterns was set initially at the monkey's median reaction time (the time from the pattern's onset to the choice response) in the last discrimination training session. The exposure duration was then titrated according to the following rule: when the monkey performed correctly on three consecutive trials, the duration was reduced by $10 \mathrm{~ms}$; when the monkey made an error or failed to respond within $5 \mathrm{~s}$ of the pattern's appearance, the duration was increased by $10 \mathrm{~ms}$. The exposure duration was never less than $10 \mathrm{~ms}$ owing to mechanical limitations of the shutter. In all other respects, the procedures were the same as those used in pattern discrimination training. The exposure duration on the initial trial of each daily session after the first session was the same as it was on the last trial of the previous session. Titration testing continued until the monkeys met a criterion of stability over 16 consecutive sessions: the standard deviation of the mean exposure durations on each of the sessions had to be less than or equal to $20 \%$ of the mean exposure duration averaged over the same sessions. In the same 16 sessions, the monkeys were also required to show no improvement (the mean daily exposure durations averaged over the last eight sessions had to be greater than or equal to the mean daily exposure durations averaged over the eight previous sessions). One monkey (SC-1) stopped testing after 13 titration sessions. It was then retrained to press the panels and perform the pattern discrimination to criterion; a re-run correction procedure was used in discrimination training to maintain its performance. Subsequently, this monkey completed titration testing.

\section{Surgical procedures}

Bilateral lesions of the pulvinar and superior colliculus were made by radiofrequency thermocoagulation. The lesioning sites within the pulvinar were selected by making microelectrode recordings from the caudal pole of the lateral geniculate, which is adjacent to the inferior pulvinar. Likewise, lesioning sites within the superior colliculus were chosen on the basis of receptive field positions of colliculus units, also recorded with microelectrodes. Detailed descriptions of these procedures are given in Bender and Baizer (1984) and Butter et al. (1978). Before receiving colliculus or pulvinar lesions, two monkeys (SC-1 and PUL-2) received sham operations, after which they were retested for visual search. In sham surgery, electrodes were lowered into the pulvinar or superior colliculus, but no current was passed.

\section{Histological procedures}

Following the completion of all testing, the monkeys were perfused intracardially under deep anesthesia (sodium pentobarbi- tal) with $0.9 \%$ saline followed by $10 \%$ formalin in saline. A block of brain tissue containing the thalamus and tectum was cut in stereotaxic planes, removed, hardened in formalin and then in sucrose-formalin, and embedded in albumin-gel. Frozen sections, $33 \mu \mathrm{m}$ in thickness, were cut through the region of the lesion. Two series of sections, taken at $0.2 \mathrm{~mm}$ intervals through the thalamus and midbrain, were stained: one for Nissl substance with cresyl violet, and a second for myelin with the Heidenhaine-Woelke method. The sections were examined microscopically and the damaged areas plotted on standard brain drawings.

\section{Results}

\section{Histological findings}

Representative cross sections through the superior colliculus and pulvinar lesions are shown in Figs. 2 and 3 . The superior colliculus, including its deep layers, was either totally destroyed (SC-1) or showed only very small intact regions (SC-2, SC-3). The colliculus lesions also extended into other nearby structures to varying degrees. The dorsal portion of the anterior central gray was slightly damaged in all three brains. The posterior third of the pretectal region showed variable damage. The extent of the pretectal lesion was greatest in SC-2, in which it included the olivary pretectal nucleus; this structure was spared on SC-3's left side. The lesions in SC-1 and SC-3 extended rostrally into the habenular region and involved the right paraventricular nucleus in SC-1, and the left dorsomedial and parafascicular nucleus in SC-3. The inferior colliculus was very slightly damaged on the left in SC-3 and bilaterally in $\mathrm{SC}-2$. The ventromedial edge of the posterior pulvinar showed cell loss in SC-1.

The pulvinar lesions in all three monkeys produced massive bilateral loss of the inferior and lateral portions of this structure (see Fig. 3). In particular, the zone receiving input from the superficial tectal layers, which includes the intergeniculate portion of the inferior pulvinar, was severely damaged. Within this zone, only the left (in PUL-2) or right (in PUL-3) ventromedial portion of the intergeniculate region was spared. In addition, other parts of the pulvinar were damaged to varying degrees. The lateral pulvinar was totally destroyed in PUL-3, and its ventral half was severely damaged in the other two brains. PUL-3 also showed extensive cell loss in the medial pulvinar, whereas this region was only slightly damaged in PUL-1 and PUL-2. Thus, the region implicated by Petersen et al. (1984) in impaired shifts of attention was totally destroyed in PUL-3, and partially damaged in PUL-1 and PUL-2. The lateral geniculate bodies were virtually intact in all three monkeys; very slight damage was found bilaterally along the posteromedial edge of the geniculate in 

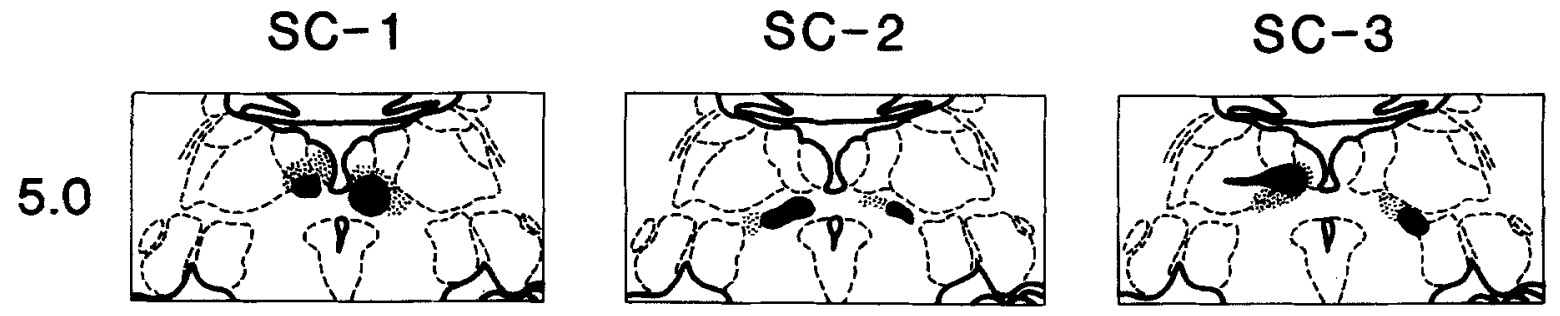

4.2
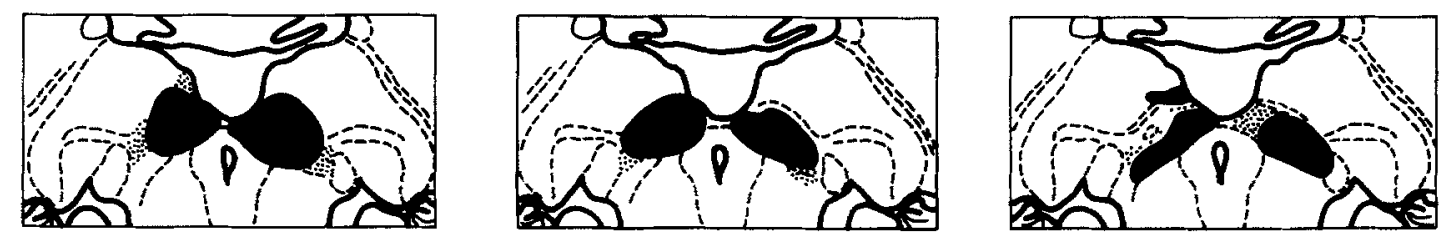

3.4
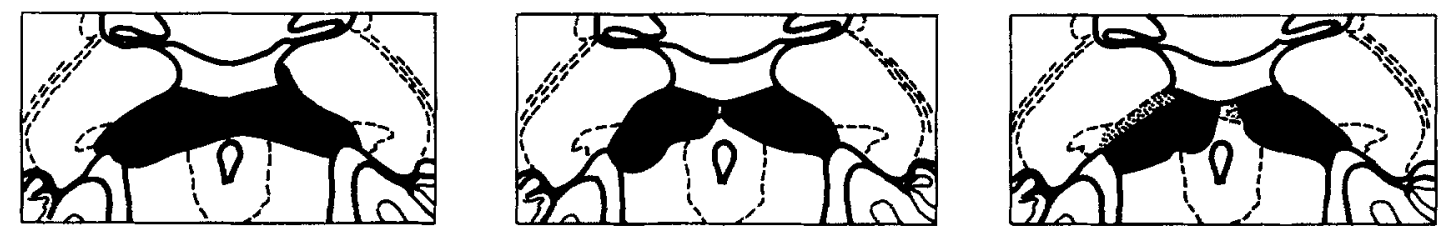

2.6
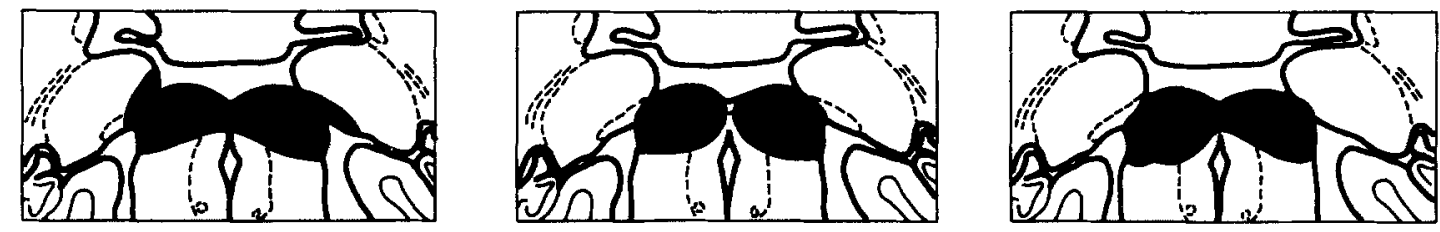

1.8
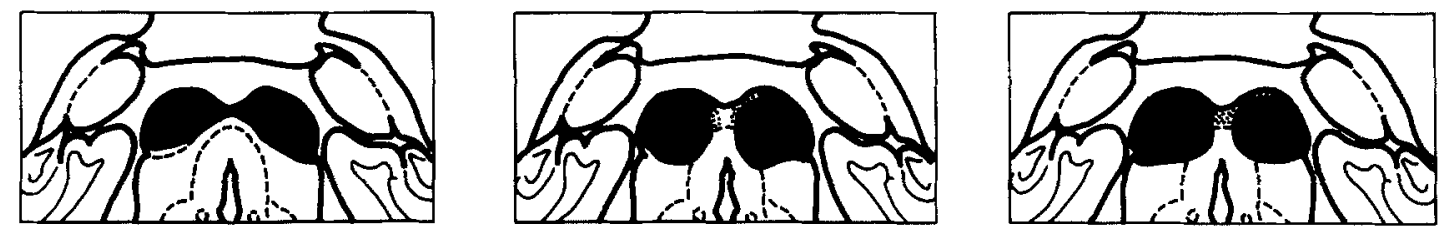

1.0
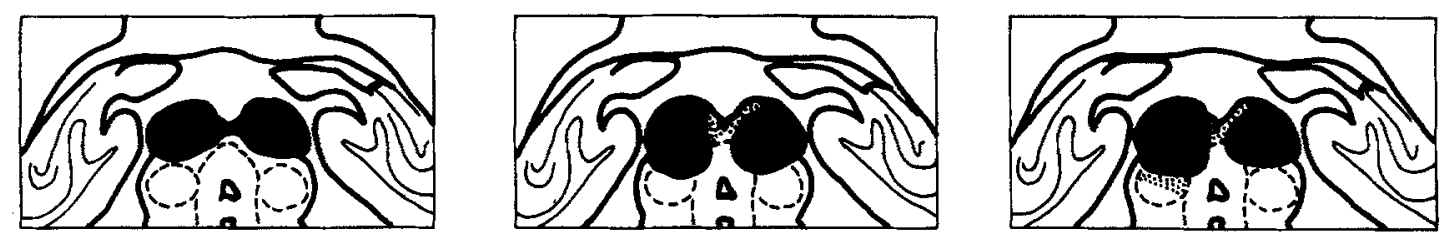

Fig. 2. Reconstructions of the superior colliculus lesions shown on standardized coronal sections. Areas of total cell loss shown in black, areas of partial cell loss and heavy gliosis shown as stippled. Numbers in left column indicate approximate stereotaxic A-P level of the sections

PUL-3, and unilaterally in the geniculate's posteromedial portion in PUL-2. Examination of myelinstained cross sections showed that the pulvinar lesions resulted in massive, bilateral loss of fibers in the brachium of the superior colliculus in all 3 animals. The loss of brachial fibers in PUL-3 appeared to be total.

Visual search task

Following control surgery. Two monkeys (SC-1 and PUL-2) were tested after control surgery. Neither showed altered search performance. Both their search times, defined as the interval between pressing the central panel and a choice response (CR) panel, and their errors in choice responses (pressing the wrong CR panel) were the same as before surgery.

Following superior colliculus lesions. All three monkeys showed essentially complete retention of the discrimination between the target pattern and each of the irrelevant patterns. After a maximum of 5 retraining sessions, they performed this discrimination at preoperative levels. 

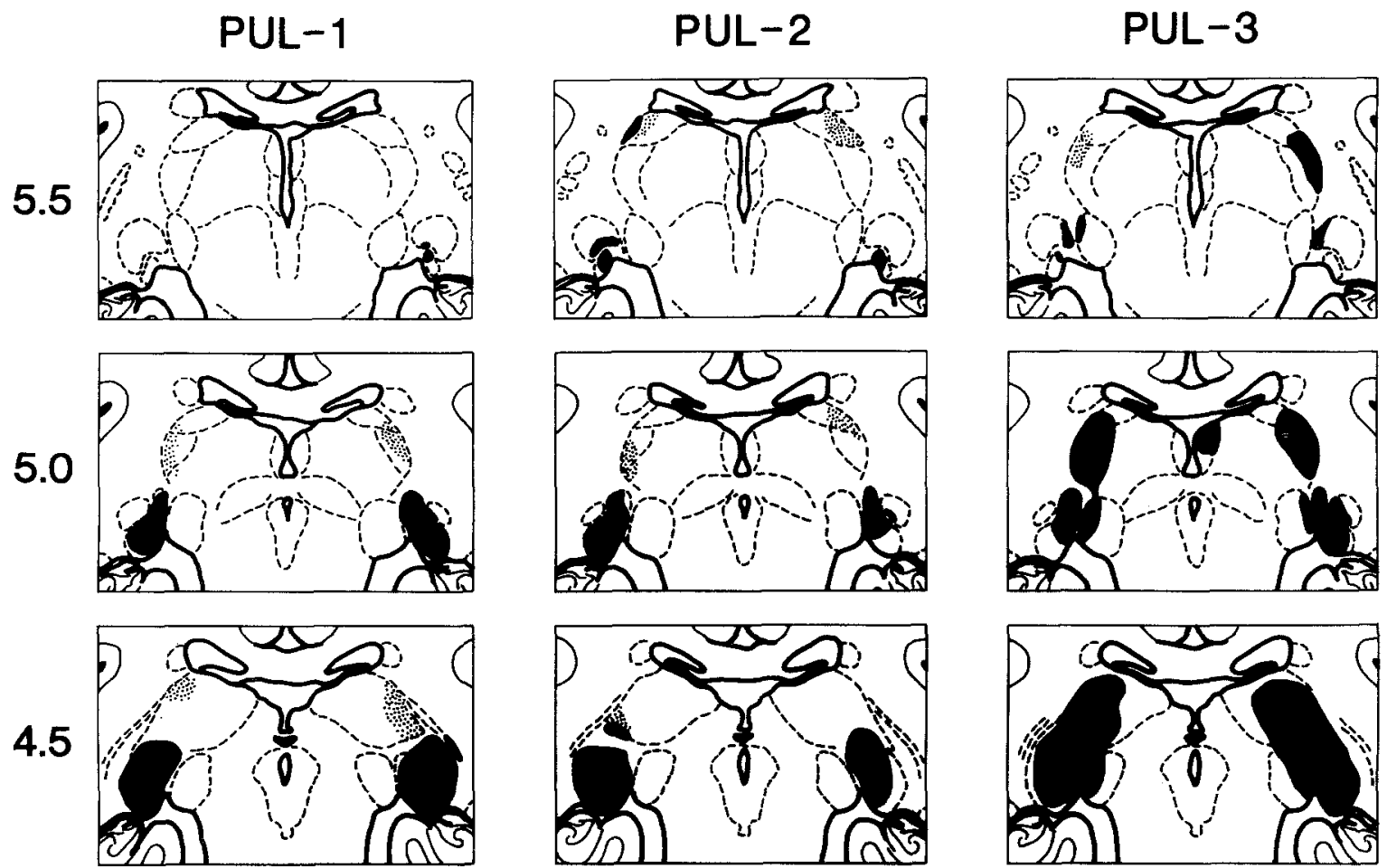

4.0
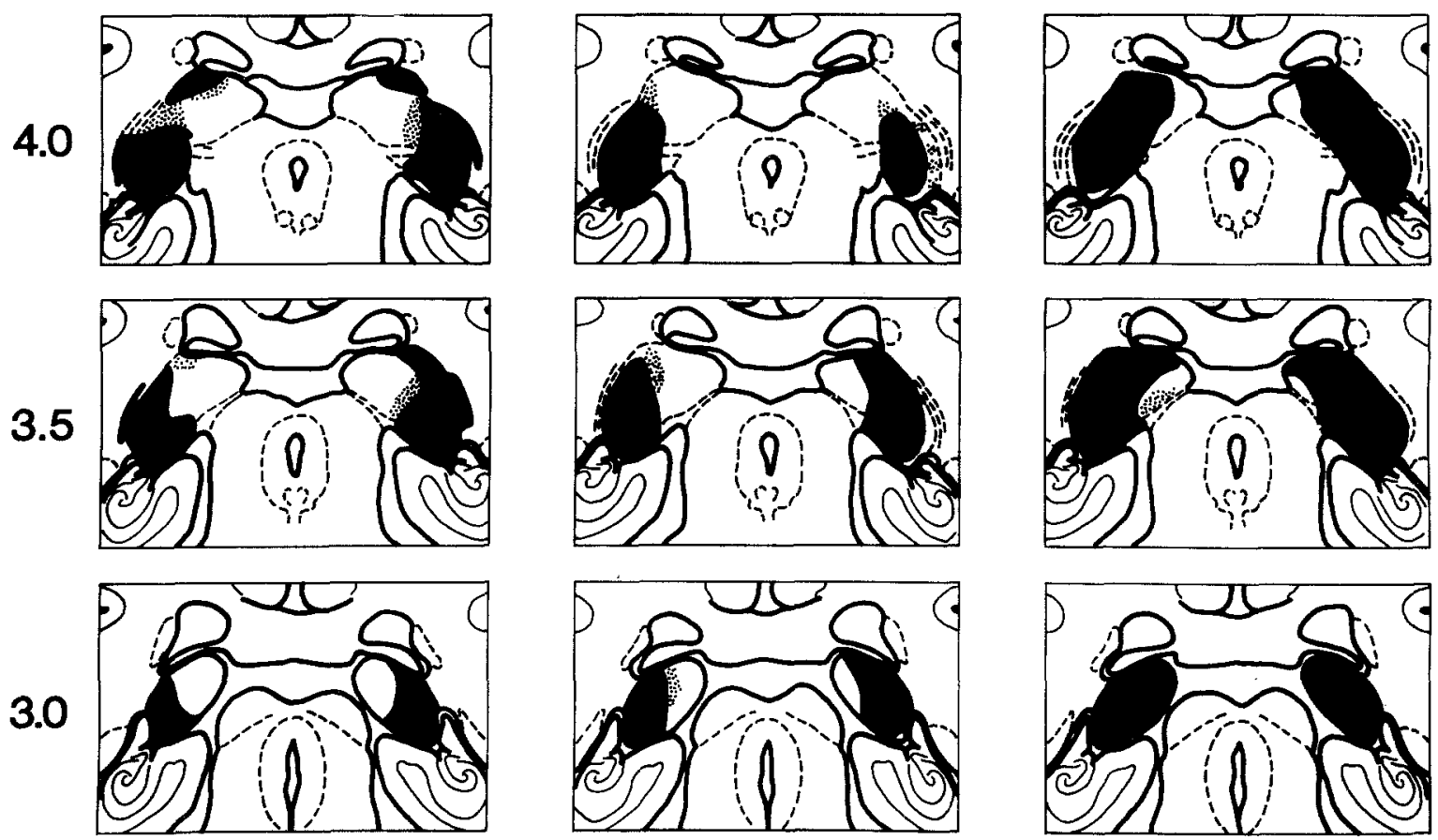

Fig. 3. Reconstructions of the pulvinar lesions. Conventions as in Fig. 2

In the visual search tests, all three animals were severely impaired in either search time, percent errors, or both. Figure 4 shows the differences between postoperative and preoperative performance for all three animals. Each animal's search times on errorless trials in each contrast condition were analyzed by a four-way, mixed design ANOVA in which the variance attributable to the operation, target eccentricity, number of irrelevant patterns, testing sessions (nested in the pre-postoperation factor) and their interactions were calculated. Each monkey's percent errors (to which $1 \%$ was added in 
SC-1
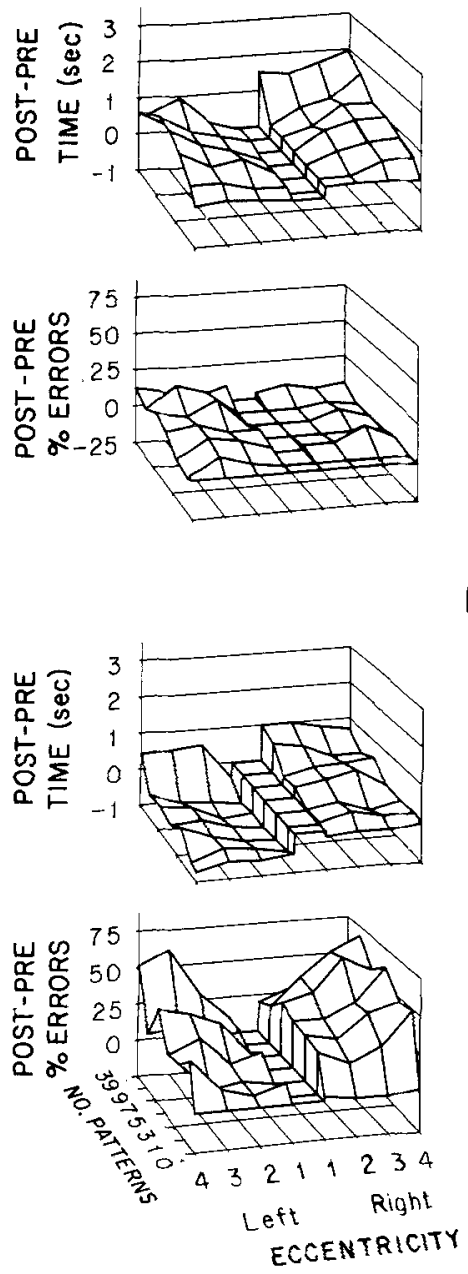

\section{HIGH CONTRAST}
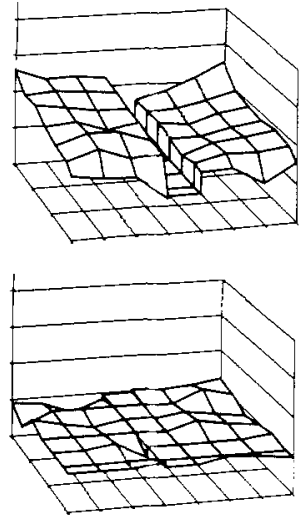

\section{LOW CONTRAST}
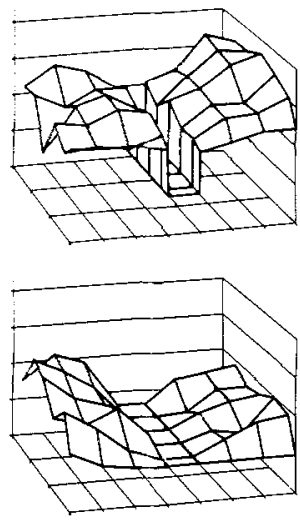

order to remove zero scores) were analyzed by a three-way ANOVA in which the variance due to the operation, target eccentricity, number of irrelevant patterns and their interactions, all averaged over testing sessions, were calculated. All statistical tests were two-tailed.

SC-1 showed the most consistent impairments following surgery. As seen in Fig. 4, its functions relating search time to target eccentricity and to the number of irrelevant patterns were considerably steeper following surgery than before surgery. These changes were found in both contrast conditions and were more prominent when the target appeared on the right $C R$ panel. Similar changes were found in $\mathrm{SC}-1$ 's functions relating errors to target eccentricity and number of irrelevant patterns, particularly in the low-contrast condition, in which error rates reached $75 \%$. These observations were borne out by the ANOVAs for both contrast conditions, which

\section{$\mathrm{SC}-3$}
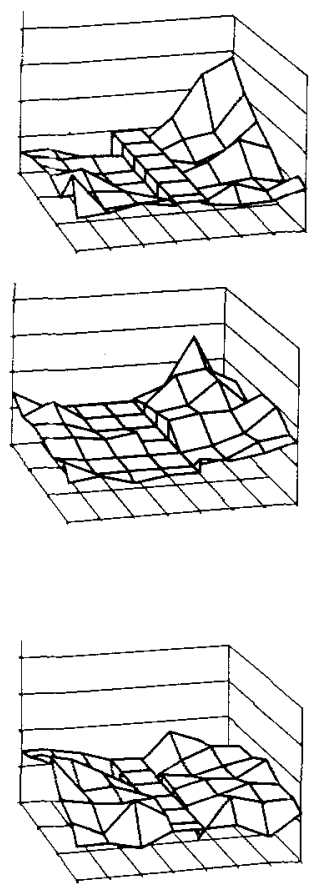

Fig. 4. Visual search performance of animals with superior colliculus lesions. Three-dimensional plots of the difference between postoperative and preoperative search time and percent errors as a function of number of distracting patterns and target eccentricity, Target appeared within one of the 4 eccentricity ranges that are shown in Fig. 1 , on either the left or right choice panel. Search time is the median reaction time per session per stimulus condition, averaged over sessions; \% errors were likewise averaged over sessions. Target and distracting patterns were presented at high contrast for the top 2 rows, and at low contrast for the bottom 2 rows revealed significant interactions of operation $\mathrm{x}$ target position and operation $\mathrm{x}$ number of irrelevant patterns for both response measures and contrast conditions (see Table 1).

Following surgery, SC-2 showed steeper functions relating search time to target eccentricity and number of irrelevant patterns in the low contrast condition, but not in the high contrast condition. The same was true for error rates: in the low contrast condition, errors increased with target eccentricity and number of irrelevant patterns far more rapidly than they had preoperatively. In the high contrast condition, errors were little affected by surgery. These changes in SC-2's performance were reflected in the ANOVA as significant interactions between the effects of the operation and stimulus variables in the low contrast condition (see Table 1).

Following surgery, SC-3's functions relating search time and errors to both stimulus variables 
Table 1. Statistical analysis of visual search findings

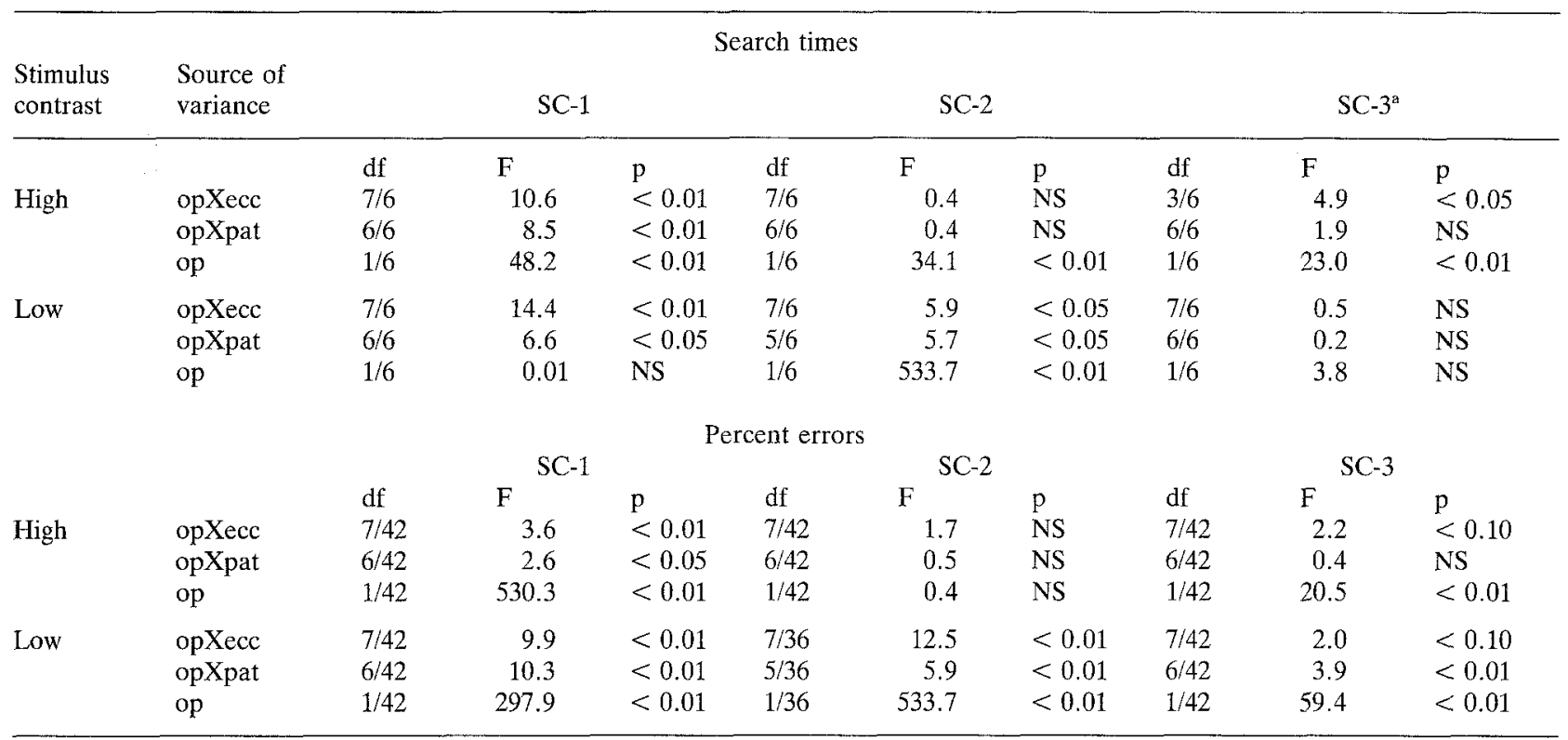

${ }^{a}$ Analysis of search times in high contrast condition limited to trials when target was on the right CR panel

\section{PUL-1}
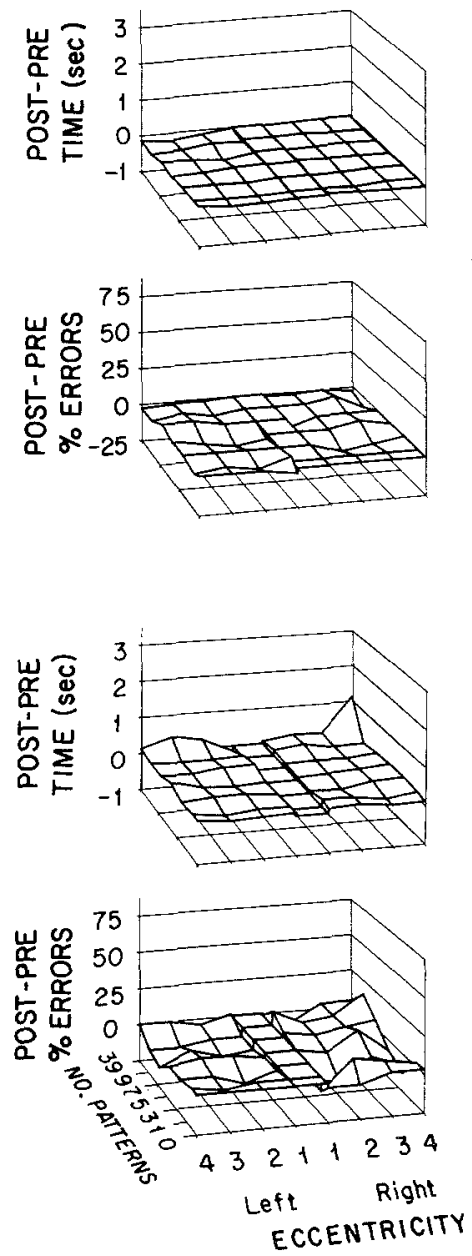

PUL-2 HIGH CONTRAST
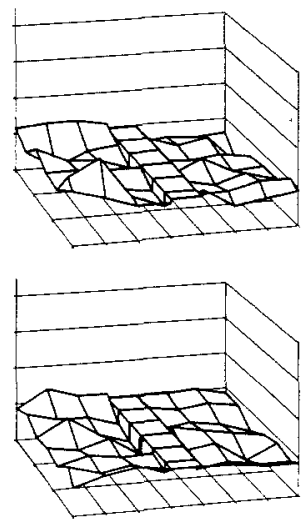

LOW CONTRAST
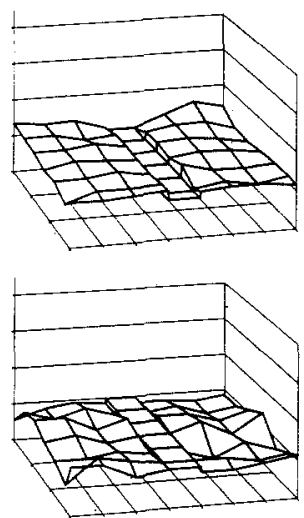
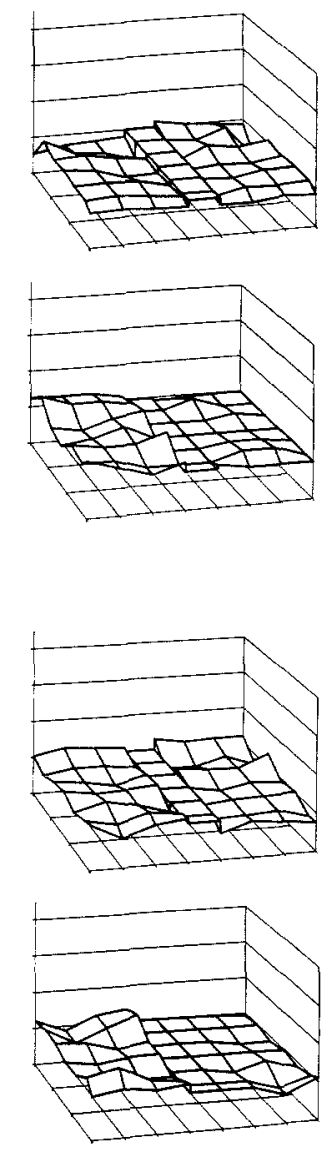

\section{PUL-3}

Fig. 5. Visual search performance of animals with pulvinar lesions. See legend to Fig. 4 
Table 2. Visual search for a new target

\begin{tabular}{lcr}
\hline Subject & Trials to criterion & Total errors \\
\hline UC-1 & 3,300 & 910 \\
UC-2 & 2,420 & 752 \\
UC-3 & 4,620 & 1,173 \\
Mean & 3,447 & 945 \\
SC-1 & $11,000^{\mathrm{b}}$ & 3,842 \\
SC-2 & 1,980 & 298 \\
SC-3 & 11,000 & 3,149 \\
Mean & 4,660 & 2,430 \\
PUL-1 & 2,640 & 648 \\
PUL-2 & 2,420 & 736 \\
PUL-3 & 5,060 & 987 \\
Mean & 3,373 & 790
\end{tabular}

a Includes criterion sessions

${ }^{\mathrm{b}}$ Failed to meet criterion; performance on last session $=74 \%$ correct

were steeper than they were before surgery, but only when the target was presented on the right $C R$ panel (see Fig. 4). Hence, the ANOVAs of this animal's data were performed only for trials when the target was presented on the right. The statistical analysis revealed that postoperatively its search times increased significantly with target position in the high contrast condition, and its errors increased significantly with increasing distractors at low contrast (see Table 1).

Following pulvinar lesions. Whereas all monkeys with colliculus lesions were impaired in the visual search testing, the monkeys with pulvinar lesions showed very little or no impairment in these tests (see Fig. 5). PUL-1 and PUL-2 showed slight but non-significant increases in search times when the target appeared on the right under the most difficult conditions, i.e., low contrast, 39 distractor patterns and maximum target eccentricity. PUL-3 also showed no significant postoperative increase in search times, but did make slightly more errors under both contrast conditions when the target appeared on the left CR panel (see Fig. 5). However, ANOVAs of PUL-3's data, like those of the other two monkeys, showed that none of the interactions between the effect of surgery and stimulus variables were significant.

\section{Visual search for a new target}

The number of trials to criterion and errors made in reaching criterion for each of the three groups of animals are shown in Table 2. In comparison to the unoperated control monkeys, two of the monkeys

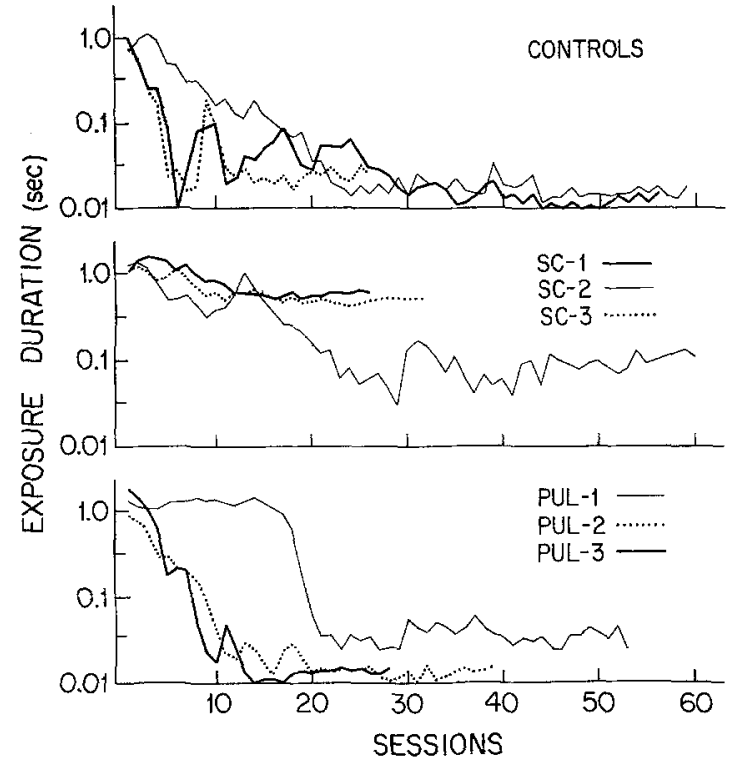

Fig. 6. Average exposure duration for each session during tachistoscopic pattern-discrimination titration testing. Top, unoperated control animals; middle, animals with superior colliculus lesions; bottom, animals with pulvinar lesions

with colliculus lesions, SC-1 and SC-3, were impaired in acquiring this visual search task. SC-1 failed to attain $90 \%$ correct responses in 50 sessions, although it performed above chance on the last session; SC-3 attained the criterion in the 50th session and made many more errors than did the control monkeys. The search times of both animals were also longer than those of the normal monkeys, especially when the target was presented in more eccentric positions. SC2 performed in the range of the control monkeys.

As can be seen in Table 2, the scores of the monkeys with pulvinar lesions were within the normal range; only one of them, PUL-2, took slightly more trials than the slowest control animal to achieve criterion. Furthermore, the search times of the pulvinar-lesioned animals were not different from those of the unoperated control monkeys.

\section{Tachistoscopic pattern discrimination}

The results of training and testing are summarized in Table 3 and Fig. 6 . The groups did not differ in the number of sessions required to learn the light-flash detection task nor in the rapidity with which they learned the pattern discrimination. In the pre-criterion phase of titration testing, the total number of sessions required by the monkeys to reach the criterion of stability varied considerably, as did the mean exposure durations (see Table 3 ); consequently there were no group differences in these measures. 
Table 3. Tachistoscopic pattern discrimination performance

\begin{tabular}{|c|c|c|c|c|c|c|}
\hline \multirow[b]{3}{*}{ Subject } & \multicolumn{2}{|c|}{ Pre-titration testing } & \multicolumn{4}{|c|}{ Pattern titration testing } \\
\hline & \multirow{2}{*}{$\begin{array}{l}\text { Light flash } \\
\text { detection } \\
\text { Trials } \\
\text { to crit }\end{array}$} & \multirow{2}{*}{$\begin{array}{l}\text { Pattern } \\
\text { discrim } \\
\text { Trials } \\
\text { to crit }\end{array}$} & \multicolumn{2}{|c|}{ Pre-criterion run } & \multicolumn{2}{|c|}{ Criterion run } \\
\hline & & & $\begin{array}{l}\text { Trials } \\
\text { to crit }\end{array}$ & $\begin{array}{l}\text { Mean exp } \\
\text { duration }\end{array}$ & $\begin{array}{l}\text { Percent } \\
\text { correct }\end{array}$ & $\begin{array}{l}\text { Mean exp } \\
\text { duration }\end{array}$ \\
\hline UC-1 & 2310 & 1470 & 8400 & 0.08 & 90 & 0.012 \\
\hline UC-2 & 4620 & 1680 & 2100 & 0.20 & 82 & 0.025 \\
\hline UC-3 & 6090 & 1050 & 9030 & 0.16 & 86 & 0.013 \\
\hline Mean & 4340 & 1400 & 6510 & 0.15 & 86 & 0.017 \\
\hline $\mathrm{SC}-1^{\mathrm{a}}$ & 2940 & $2100(1890)^{b}$ & 2100 & 1.05 & 81 & 0.58 \\
\hline $\mathrm{SC}-2$ & 4830 & 1260 & 9240 & 0.31 & 78 & 0.10 \\
\hline SC-3 & 3360 & 2520 & 3360 & 0.78 & 82 & 0.49 \\
\hline Mean & 3710 & 1960 & 4900 & 0.71 & 80 & 0.39 \\
\hline PUL-1 & 3570 & 1050 & 7770 & 0.61 & 82 & 0.034 \\
\hline PUL-2 & 5040 & 1050 & 8190 & 0.16 & 86 & 0.013 \\
\hline PUL-3 & 3150 & 2310 & 2520 & 0.48 & 89 & 0.013 \\
\hline Mean & 3920 & 1470 & 6160 & 0.42 & 86 & 0.020 \\
\hline
\end{tabular}

${ }^{a}$ Stopped testing after 13 titration sessions. Retrained on N vs. Z discrimination in 18 sessions. Numbers refer to 2 nd titration series

${ }^{b}$ Required correction re-run procedure in relearning

However, group differences did emerge during the criterion phase of the titration procedure. The average exposure duration titration by the colliculuslesioned animals was much longer than that of the controls (see Table 3 and Fig. 6). Two of the colliculus-lesioned animals stabilized at durations almost 30 times longer than the average control duration. In contrast, the performance of the monkeys with pulvinar lesions did not differ from that of the control monkeys. The average exposure durations attained by PUL-2 and PUL-3 were within the range of control values; the average exposure attained by PUL- 1 was only 9 ms longer than the longest value attained by the controls.

The performance of the normal and pulvinarlesioned monkeys during the criterion run was slightly higher than the approximately $80 \%$ level of performance expected with this titration procedure (Wetherill and Levitt 1965). This was probably due to the animals' frequent titration of the exposure duration to the lowest value $(10 \mathrm{~ms})$ produced by the shutter; thus, the task could not have been made more difficult for them. Indeed, those animals with the shortest durations also had the highest percent correct. The colliculus-lesioned animals, on the other hand, achieved the expected levels of $80 \%$ correct, presumably because the exposure durations that they titrated were well above the minimum duration.

\section{Discussion}

The main findings in these experiments were first, that superior colliculus lesions impaired visual search performance whereas large pulvinar lesions, which also destroyed most of the corticotectal tract, had little or no effect on search performance and second, that tachistoscopic discrimination thresholds were elevated by colliculus lesions but not by pulvinar lesions. We discuss each of these results in turn.

\section{Visual search}

The colliculus lesions did not impair detection, since postoperative search times and errors did not increase when only the target was present ( 0 distracting stimuli). Rather, as the number of irrelevant patterns increased, the monkeys with colliculus lesions showed much greater increases in search times and errors than they had before surgery. Furthermore, both errors and search times increased more with target eccentricity after surgery than before. However, the colliculus lesions did not appear to alter the monkeys' basic search strategies as revealed by analyses of their search times in preoperative tests (see Azzato and Butter 1984); following surgery, they continued to show systematic increases in search time as target eccentricity increased. Thus, the lesions appeared to slow visual search, but did not disorganize it.

Variations in the nature and severity of the monkeys' deficits were not correlated with the extent of damage either to the colliculus or to neighboring structures. For example, damage to midline thalamic nuclei, which have been implicated in control of saccades to visual targets (Albano et al. 1982), and to 
the habenula, was most severe on the left side in SC-3 and less severe in SC-2. However, SC-3 was the least impaired of the three monkeys. Furthermore, whereas SC-3 was impaired only when the target was presented on the right $\mathrm{CR}$ panel, this impairment was not more severe than those of the other two monkeys. With regard to the pretectum, SC-2 sustained the most severe lesion of this area, and SC-3 the least. However, the extent of pretectal damage was difficult to determine. For this reason and because the pretectum has been implicated in the control of both conjugate and vergence eye movements (Pasik et al. 1969; Lawler and Cowey 1986), pretectal damage should not be ruled out as a possible factor contributing to the impairments, although the monkeys with colliculus lesions did not chronically show signs of pretectal damage, such as dilated pupils or retracted lids. While the colliculus lesions were all extremely large, and virtually complete in SC-1, the small differences among them, alone or in combination with damage to the pretectum or other nearby structures, might account for some of the variation in the behavioral impairments.

The impairments described above are most easily attributable to deficient oculomotor function that has been described following colliculus lesions. In particular, colliculus lesions produce a persistent and marked reduction in both saccadic amplitude and frequency during scanning of a visual array (Schiller et al. 1980; Kurtz and Butter 1980). These saccadic abnormalities should produce increasingly poor performance as a search task requires more saccades, as was the case in the present experiment: increasing either target eccentricity or number of irrelevant patterns (thereby requiring more saccades to search through all patterns) led to longer search times following the lesions. Likewise, the increased errors under these conditions probably reflect a failure to perform saccades of sufficient amplitude to fixate accurately, and thus recognize, the target (Kurtz and Butter 1980). The considerable variation among the animals in the nature and severity of the deficit probably reflects the idiosyncratic adaptation of each animal to these oculomotor abnormalities. Some animals may have persisted in looking for the target, thus increasing their search times, while others may have given up after a cursory search and pressed a $\mathrm{CR}$ panel at random, thus increasing errors, but not search times. The impaired learning of the colliculuslesioned monkeys in the visual search for a new target presumably reflects a similar inability to make eye movements sufficiently accurate to identify the new target, which like the original target in the first visual search task, was presented at randomlyassigned positions within the large CR panels. This explanation would be consistent with the finding that reducing eye movements, or the opportunity to look at the cues, retards pattern discrimination learning in two-choice discriminations (Schrier and Povar 1982).

In contrast to the colliculus lesions, pulvinar lesions did not significantly alter visual search performance. In interpreting this result, we emphasize that the pulvinar lesions damaged two distinctly different neuronal systems. First, the tectorecipient zones of the pulvinar were extensively damaged. The target of the superficial layers of the colliculus sustained massive bilateral cell loss in all three animals. The target of the deep layers includes the lateral margin of the lateral pulvinar and a more central region composed of part of the medial pulvinar and an adjacent part of the lateral pulvinar (Harting et al. 1980). The lateral zone was severely or completely ablated in all three animals. The central zone was slightly damaged in two animals, but showed virtually total cell loss in PUL-3. Second, there was severe damage to corticotectal fibers, which pass through the pulvinar before collecting together and entering the colliculus through its brachium (Bender and Baizer 1984). These fibers were greatly reduced in two animals and totally destroyed in PUL-3.

Considering first damage to the pulvinar per se, the present results, like our previous ones (Leiby et al. 1982; Nagel-Leiby et al. 1984), fail to support the view that the pulvinar shares visual functions with the superior colliculus, from which it receives projections. Neither destruction of the part of the pulvinar receiving superficial tectal input (all three monkeys) nor of the part receiving deep tectal input (PUL-3), resulted in behavioral deficits in the visual search task, whereas colliculus lesions did. Thus, the functions of the tecto-pulvinar pathway apparently are not critical to a variety of visually guided behaviors. Neither well-practiced visual search, learning of a new target in the context of a visual search, discrimination learning with stimulus-response separation (Nagel-Leiby et al. 1984), localization of brief light flashes (Leiby et al. 1982), nor saccadic acquisition of visual targets (Bender and Baizer 1986), are substantially affected by pulvinar cell loss, despite the fact that tectal lesions impair all of these behaviors. There remain, of course, a broad variety of visual behaviors which have yet to be examined following pulvinar lesions.

The inferior (Chalupa et al. 1976) and dorsolateral (Petersen et al. 1984) pulvinar have each been implicated indirectly in controlling shifts of attention in visually-guided behavior. The present results suggest that the pulvinar is not essential for the shifts of attention that occur during visual search. Several 
explanations for this apparent discrepancy can be considered. First, if the pulvinar does play a role in shifting attention, its contribution might only become critical when the shift is large, e.g., from the current fixation point to a far peripheral target. On this view, one would expect little impairment since the monkeys apparently searched systematically through the display panels, and thus their gaze and attention shifts were rarely very peripheral to current fixation. However, this explanation seems unlikely; it predicts that search performance should be worse when the number of distractor patterns is small, since on those trials the distance between stimuli is frequently large. This was not the case, although the pulvinar-lesioned animals did show a slight and non-significant increase in errors when few distractor patterns were present.

A second possibility is that the pulvinar plays a crucial role in shifting attention only in the initial stages of visual search when the animal is still learning the relevant cues which distinguish the target from the irrelevant display elements. However, this seems unlikely since in the second search task the pulvinar-lesioned animals did not require more trials than their controls to learn to respond to a new target not previously seen. This lack of impairment could have resulted from slow learning rates of the unoperated monkeys, which had less experience in the original search task than did the operated monkeys. However, there is no evidence that reduced experience with the original search task for monkeys within the unoperated group impeded their learning of the second visual search task. Rather, the opposite occurred: UC-2 required half as many trials as UC-3 to learn the original discrimination, yet learned the search for a new target in less trials than UC-3 required. In any case, the pulvinar-lesioned monkeys learned the new search task in many fewer trials than the two impaired monkeys with colliculus lesions.

A third possible explanation for the apparent discrepancy is that the pulvinar-lesioned animals in our study had an impairment in shifting attention that was too subtle, or too short-lived, for our procedures to detect. If so, the deficit must have been considerably more subtle than that produced by tectal lesions. But it should be noted that the small changes in reaction time attributable to impaired attention in the Petersen et al. (1984) study (a few tens of milliseconds) could easily have gone undetected in the present study.

Considering next damage to the corticotectal fibers, we were surprised to find that the pulvinarlesioned monkeys were unimpaired in visual search; the ability to shift attention spatially seemed to be the one common factor in tasks in which the corticotectal tract appears to be crucial (Leiby et al. 1982; NagelLeiby et al. 1984; Bender and Baizer 1984). The possibility that the corticotectal tract contributes to only those shifts of gaze or attention directed into the far periphery seems unlikely, for reasons mentioned above. A second possibility is that the corticotectal tract plays a crucial role in visually-guided behavior only when eye-hand coordination is critical. This factor was present in both the localization and stimulus-response separation tasks, in which the monkeys directed manual responses to the stimuli, but probably was absent in the present task since the monkeys did not reach for the target when they pressed the display screen on which it appeared.

The failure to find a search deficit after massive corticotectal tract damage raises the question what afferent systems to the colliculus are critical for visual search performance. Since the brachium of the colliculus was entirely destroyed in PUL-3, neither retinal afferents nor cortical afferents from the occipital or parietal lobes, both of which travel through the brachium, are likely to be crucial. Afferents from the frontal eye-fields are also unlikely to play a major role, since the effects of frontal eye-field lesions on visual search are far less severe than the effects of colliculus lesions (Latto 1978). However, one afferent system that may be crucial is the nigrotectal pathway. These fibers were undoubtedly spared by the pulvinar lesions, since they approach the colliculus by a route far medial and ventral to the lesions (Jayaraman et al. 1977). Furthermore, interference with this pathway, by means of muscimol injection into the colliculus, produces a marked deficit in saccades made to "remembered" targets (Hikosaka and Wurtz 1985), and this type of oculomotor dysfunction could easily lead to the search deficit we found.

\section{Tachistoscopic discrimination}

The main finding of this experiment was that the pulvinar-lesioned animals were able to discriminate stimuli at durations as brief as those of the normal animals. By contrast, the colliculus-lesioned animals could not discriminate between the stimuli unless their exposure duration was more than an order of magnitude longer than it was for intact animals. The finding that two pulvinar-lesioned animals and two intact animals titrated exposure durations close to the minimum exposure duration available suggests that the pulvinar-lesioned group might have been impaired had shorter durations been available. However, this seems unlikely; even if both intact animals had titrated durations shorter than the two lesioned 
animals, there still would have been no significant group difference in exposure duration. According to Chalupa et al. (1976), tachistoscopic discrimination is "highly demanding of attention". If so, then whatever effect pulvinar lesions have on behavior, it cannot be a simple failure of attention.

The reason for the discrepancy between the present results and those of Chalupa et al. (1976) is not clear, although a number of possibilities may be considered. The discrepancy is not likely to be due to a difference in the pulvinar lesions: ours were much more extensive than those of Chalupa et al., and included all of the region destroyed in their impaired animals. Nor do our behavioral measures lack sufficient sensitivity to detect a deficit in this task, since the colliculus-lesioned animals required a profound lengthening of the exposure duration. It is also unlikely that a difference in stimulus size (our's were larger than those of Chalupa et al.) could account for the different results. However, a procedural difference between the two experiments might be responsible for the discrepancy. Since the animals of Chalupa et al. only had to press a lever, and did not have to fixate the center of the display in order to start each trial, there was no control over eye position when the stimuli were briefly presented. Thus, there may have been considerable trial-to-trial variability in the retinal locus of the stimuli. In contrast, in our task there was relatively little trial-totrial variation in retinal position of the stimuli since the animals were required to orient to the central panel before starting each trial. A greater variability in retinal position of the stimuli may thus have been the critical factor responsible for the deficit in Chalupa et al.'s study. Damage to the corticotectal tract, which almost certainly accompanied Chalupa et al.'s lesions, does indeed impair detection and localization of brief stimuli that vary in retinal locus from trial to trial (Leiby et al. 1982). Finally, it is possible that the greater amount of prior test experience of our monkeys, compared to that of the monkeys of Chalupa et al., may have been a contributing factor. Test experience could not, however, explain the difference in performance between the pulvinar-lesioned and colliculus-lesioned animals.

Whatever the reason for the differing results, it is clear that neither substantial damage to the pulvinar itself, nor to the corticotectal tract, impairs tachistoscopic discrimination performance when measured with a titration procedure. Thus, it is difficult to accept the view that the pulvinar is critically involved in the attentional mechanisms required for tachistoscopic discrimination.

It is unlikely that the failure of the colliculuslesioned animals to perform the pattern discrimina- tion when the exposure duration was short was due simply to a detection loss, since they were unimpaired in the previous detection task, in which the duration of the light-flash $(10 \mathrm{~ms})$ was considerably shorter than the final duration they achieved during the pattern titration test. Nor is it likely that their impairment in the titration test was directly due to slow and inaccurate eye movements, since stimulus presentation was too brief to permit their foveation. However, it is possible that defective eye movements in the colliculus-lesioned animals may have been accompanied by impaired shifts of spatial attention, which in turn may have impaired discrimination performance. There is evidence that moving the eyes to a target exposed too briefly to be fixated enhances its detection, and its identification if the target is a pattern (Posner 1980; Remington 1980; Singer et al. 1977; Bryden 1961; Crovitz and Daves 1962).

\section{Is there a "second visual system"?}

The notion of a "second visual system", involving ascending links between colliculus, pulvinar, and prestriate cortex, has been a persistent and popular one. Whereas there have been many suggestions about the possible functional significance of this pathway, few have received direct experimental support in primates. Thus, this pathway has been thought to "relay" sensory input from colliculus to cortex, yet the visual responsiveness of pulvinar neurons does not depend on ascending input from the colliculus, but rather on descending input from visual cortex (Bender 1983). Behavioral methods have been no more successful, as lesions restricted to the pulvinar rarely impair performance. If the tectopulvinar pathway contributes to visually-guided behavior, one would expect that pulvinar lesions would lead to behavioral impairments in at least some of the visual tasks that are sensitive to colliculus lesions. Colliculus and pulvinar-lesioned monkeys have now been tested in a large number of visual tasks, including visual search (present findings), tachistoscopic discrimination (present findings and Chalupa et al. 1976), discrimination learning with a separation between stimulus and response sites (Nagel-Leiby et al. 1984), spatial localization of brief stimuli (Leiby et al. 1982), and saccadic latency (Bender and Baizer 1986). Impairments in these tasks following colliculus lesions are consistent and in some instances severe, yet in the same tasks pulvinar lesions either have no effect, produce impairments unobtainable with slight procedural variations (present findings), or produce impairments that are best attributed to damage to fibers of passage (Leiby et al. 
1982; Nagel-Leiby et al. 1984) or to neighboring brain regions.

Thus neither electrophysiological nor behavioral methods have yet provided clear support for the idea that the colliculus and pulvinar function together in some aspect of visually-guided behavior. To be sure, a number of reasons could account for the failure of the behavioral methods. The pulvinar is just one of several thalamic nuclei that receive colliculus projections (Harting et al. 1980). While radiofrequency pulvinar lesions would have interrupted tectal projections to some of these nuclei, such as the lateral geniculate nucleus, other tectal projections, such as those to the mediodorsal and ventral anterior nuclei (Harting et al. 1980), could have been spared. Conceivably these alternate routes can substitute adequately for a damaged tecto-pulvinar system. It is also possible that significant effects of damage to the tecto-pulvinar pathway may be revealed only with unilateral lesions, analogous to the observation that unilateral superior colliculus lesions produce an obvious contralateral visual neglect that is not apparent after bilateral lesions (Butter, unpublished work). Some support for this notion is provided by the recent suggestion that unilateral injection of GABArelated drugs into the pulvinar may alter reaction times obtained in visual attention tasks (Petersen et al. 1984). At present, however, the functional significance of the tecto-pulvinar pathway remains enigmatic.

Acknowledgements. Supported by grants MH26489 from the National Institute of Mental Health and EY02254 from the National Eye Institute. The authors thank Beverly Caffery and Amy Stenger for histological assistance, and Marilyn Hoy and Linda Smith for preparation of the manuscript.

\section{References}

Albano JE, Mishkin M, Westbrook LE, Wurtz RH (1982) Visuomotor deficits following ablation of monkey superior colliculus. J Neurophysiol 48: 338-351

Azzato M, Leiby C, Butter C, Bender D, Shirley D (1981) Effects of superior colliculus (SC) and pulvinar (P) lesions on visual search in cynomolgus monkeys. Soc Neurosci Abstr 7: 760

Azzato MC, Butter CM (1984) Visual search in cynomolgus monkeys: stimulus parameters affecting two stages of visual search. Percept Psychophys 36: 169-176

Bender DB (1981) Retinotopic organization of macaque pulvinar. J Neurophysiol 46: 672-693

Bender DB (1982) Receptive-field properties of neurons in the macaque inferior pulvinar. J Neurophysiol 48: 1-17

Bender DB (1983) Visual activation of neurons in the primate pulvinar depends on cortex but not colliculus. Brain Res 297 : 258-261

Bender DB, Baizer JS (1984) Anterograde degeneration in the superior colliculus following kainic acid and radiofrequency lesions of the macaque pulvinar. J Comp Neurol 228: 284-298
Bender DB, Baizer JS (1986) Effects of kainic acid lesions of the pulvinar on saccadic eye movements in monkeys. Soc Neurosci Abstr 12: 1039

Benevento LA, Davis B (1977) Topographical projections of the prestriate cortex to the pulvinar nuclei in the macaque monkey: an autoradiographic study. Exp Brain Res 30: 405-424

Benevento LA, Fallon JH (1975) The ascending projections of the superior colliculus in the rhesus monkey (Macaca mulatta). J Comp Neurol 160: 339-362

Benevento LA, Rezak M (1976) The cortical projections of the inferior pulvinar and adjacent lateral pulvinar in the rhesus monkey (Macaca mulatta): an autoradiographic study. Brain Res 108: 1-24

Bryden MP (1961) The role of post-exposural eye movements in tachistoscopic perception. Can J Psychol 15: 220-225

Butter CM (1974) Effect of superior colliculus, striate and prestriate lesions on visual sampling in thesus monkeys. J Comp Physiol Psychol 87: 905-917

Butter CM (1979) Contrasting effects of lateral striate and superior colliculus lesions on visual discrimination performance in rhesus monkeys. J Comp Physiol Psychol 93: 522-537

Butter CM, Weinstein C, Bender D, Gross CG (1978) Localization and detection of visual stimuli following superior colliculus lesions in rhesus monkeys. Brain Res 156: 33-49

Campos-Ortega J, Hayhow W (1972) On the organization of the visual cortical projection to the pulvinar in Macaca mulatta. Brain Behav Evol 6: 394-423

Chalupa LM, Coyle RS, Lindsley DB (1976) Effect of pulvinar lesions on visual pattern discrimination in monkeys. J Neurophysiol 39: 354-369

Chow K-L (1950) A retrograde cell degeneration study of the cortical projection field of the pulvinar in the monkey. J Comp Neurol 93: 313-340

Chow K-L (1954) Lack of behavioral effects following destruction of some thalamic association nuclei in monkey. AMA Arch Neurol Psychiat 71: 762-771

Crovitz HF, Daves W (1962) Tendencies to eye movements and perceptual accuracy. J Exp Psychol 63: 495-498

Goldberg ME, Wurtz RH (1972) Activity of superior colliculus in behaving monkey. II. Effect of attention on neuronal responses. J Neurophysiol 35: 560-574

Gould JE, Chalupa LM, Lindsley DB (1974) Modifications of pulvinar and geniculocortical evoked potentials during visual discrimination learning in monkeys. Electroencephalog Clin Neurophysiol 36: 639-649

Gross CG (1973) Visual functions of inferotemporal cortex. In: Jung R (ed) Handbook of sensory physiology. Springer, Berlin, pp 451-482

Harting JK, Huerta MF, Frankfurter AJ, Strominger NL, Royce GJ (1980) Ascending pathways from the monkey superior colliculus: an autoradiographic analysis. J Comp Neurol 192: 853-882

Hikosaka O, Wurtz RH (1985) Modification of saccadic eye movements by GABA-related substances. I. Effect of muscimol and bicuculline in the monkey superior colliculus. J Neurophysiol 53: 266-291

Jayaraman A, Batton RR, Carpenter MB (1977) Nigrotectal projections in the monkey: an autoradiographic study. Brain Res 135: $147-152$

Keating EG (1975) Effects of prestriate and striate lesions on the monkey's ability to locate and discriminate visual forms. Exp Neurol 47: 16-25

Kurtz D, Butter CM (1980) Impairments in visual discrimination performance and gaze shifts in monkeys with superior colliculus lesions. Brain Res 196: 109-124

Kurtz D, Leiby CC, Butter CM (1982) Further analysis of S-R 
separation effects on visual discrimination performance of normal rhesus monkeys and monkeys with superior colliculus lesions. J Comp Physiol Psychol 96: 35-46

Latto R (1978) The effects of bilateral frontal eye-field posterior parietal or superior collicular lesions on visual search in the rhesus monkey. Brain Res 146: 35-50

Lawler KA, Cowey A (1986) The effects of pretectal and superior collicular lesions on binocular vision. Exp Brain Res 63: 402-408

Leiby CC, Campbell AL, Butter CM (1978) Comparison of visual discrimination performance of rhesus and cynomolgus monkeys. Primate Newsletter 17: 1-5

Leiby CC III, Bender DB, Butter CM (1982) Localization and detection of visual stimuli in monkeys with pulvinar lesions. Exp Brain Res 48: 449-454

Mishkin M (1972) Cortical visual areas and their interactions. In: Karczmar AG, Eccles JC (eds) Brain and human behavior. Springer, New York, pp 187-208

Nagel-Leiby S, Bender DB, Butter CM (1984) Effects of kainic acid and radiofrequency lesions of the pulvinar on visual discrimination in the monkey. Brain Res 300: 295-303

Ogren MP, Hendrickson AE (1976) Pathways between striate cortex and subcortical regions in Macaca mulatta and Saimiri sciureus: evidence for a reciprocal pulvinar connection. Exp Neurol 53: 780-800

Partlow GD, Colonnier M, Szabo J (1977) Thalamic projections of the superior colliculus in the rhesus monkey, Macaca mulatta: a light and electron microscopic study. J Comp Neurol 171: 285-318

Pasik P, Pasik T, Bender MB (1969) The pretectal syndrome in monkeys. I. Disturbances of gaze and body posture. Brain 92: $521-534$

Petersen SE, Morris JD, Robinson DL (1984) Modulation of attentional behavior by injection of GABA-related drugs into the pulvinar of the macaque. Soc Neurosci Abstr 10: 475

Petersen SE, Robinson DL, Keys W (1985) Pulvinar nuclei of the behaving rhesus monkey: visual responses and their modulation. J Neurophysiol 54: 867-886

Posner MI (1980) Orienting of attention. Q J Exp Psychol 32: 3-25

Remington RW (1980) Attention and saccadic eye movements J Exp Psychol 6: 726-744

Schiller PH, True SD, Conway JL (1980) Deficits in eye movements following frontal eye-field and superior colliculus ablations. J Neurophysiol 44: 1175-1189

Schrier AM, Povar ML (1982) Eye movements of monkeys during discrimination learning: role of visual scanning. J Exp Psychol 8: $33-48$

Singer W, Zihl J, Pöppel E (1977) Subcortical control of visual thresholds in humans: evidence for modality specific and retinotopically organized mechanisms of selective attention. Exp Brain Res 29: 173-190

Ungerleider LG, Christensen CA (1979) Pulvinar lesions in monkeys produce abnormal scanning of a complex visual array. Neuropsychologia 17: 493-501

Ungerleider LG, Ganz L, Pribram KH (1977) Size constancy in rhesus monkeys: effects of pulvinar, prestriate and inferotemporal lesions. Exp Brain Res 27: 251-269

Ungerleider LG, Pribram KH (1977) Inferotemporal versus combined pulvinar-prestriate lesions in the rhesus monkey: effects on color, object and pattern discrimination. Neuropsychologia 15: 481-498

Wetherill GB, Levitt H (1965) Sequential estimation of points on a psychometric function. Br J Math Statist Psychol 50: 1-10

Whitlock PG, Nauta WJH (1956) Subcortical projections from the temporal neocortex in Macaca mulatta. J Comp Neurol 106: 183-212

Wurtz RH, Mohler CW (1976) Organization of monkey superior colliculus: enhanced visual response of superficial layer cells. J Neurophysiol 39: 745-765

Received January 13, 1987 / Accepted July 31, 1987 